\title{
Effects of creatine supplementation on homocysteine levels and lipid peroxidation in rats
}

\author{
Rafael Deminice*, Guilherme Vannucchi Portari, Helio Vannucchi and Alceu Afonso Jordao \\ Nutrition and Metabolism, Faculty of Medicine of Ribeirão Preto, University of São Paulo, Avenida Bandeirantes 3900, \\ CEP 14049-900 Ribeirão Preto, SP, Brazil
}

(Received 3 June 2008 - Revised 22 October 2008 - Accepted 23 October 2008 - First published online 15 December 2008)

Hyperhomocysteinaemia is an independent risk factor for CVD. Recent data show a relationship between homocysteine (Hcy) and free radical formation. Since creatine synthesis is responsible for most of the methyl group transfers that result in Hcy formation, creatine supplementation might inhibit Hcy production and reduce free radical formation. The present study investigated the effects of creatine supplementation on Hcy levels and lipid peroxidation biomarkers. Thirty rats were divided into three groups: control group; diet with creatine group (DCr; $2 \%$ creatine in the diet for $28 \mathrm{~d}$ ); creatine overload plus diet with creatine group $(\mathrm{CrO}+\mathrm{D} ; 5 \mathrm{~g}$ creatine/ $\mathrm{kg}$ by oral administration for $5 \mathrm{~d}+2 \%$ in the diet for $23 \mathrm{~d}$ ). Plasma Hcy was significantly lower $(P<0.05)$ in DCr $(7.5(\mathrm{SD} 1.2) \mu \mathrm{mol} / \mathrm{l})$ and $\mathrm{CrO}+\mathrm{D}(7.2$ (SD 1.7$) \mu \mathrm{mol} / \mathrm{l}) \mathrm{groups}$ compared with the control group (12.4 (SD 2.2) $\mu \mathrm{mol} / 1$ ). Both plasma thiobarbituric acid-reactive species (TBARS) (control, 10 (SD 3.4); DCr, 4.9 (SD 0.7); $\mathrm{CrO}+\mathrm{D}, 2.4$ (SD 1) $\mu \mathrm{mol} / \mathrm{l}$ ) and plasma total glutathione (control, 4.3 (SD 1.9); DCr, 2.5 (SD 0.8); CrO + D, 1.8 (SD 0.5) $\mu \mathrm{mol} / \mathrm{l})$ were lower in the groups that received creatine $(P<0.05)$. In addition, Hcy showed significant negative correlation $(P<0.05)$ with plasma creatine $(r-0.61)$ and positive correlation with plasma TBARS $(r 0.74)$. Plasma creatine was negatively correlated with plasma TBARS $(r-0.75)$ and total peroxide $(r-0 \cdot 40)$. We conclude that creatine supplementation reduces plasma Hcy levels and lipid peroxidation biomarkers, suggesting a protective role against oxidative damage. Modulating Hcy formation may, however, influence glutathione synthesis and thereby affect the redox state of the cells.

Creatine supplementation: Methyl balance: Homocysteine: Lipid peroxidation

Over the last few years, increasing evidence has shown that hyperhomocysteinaemia is an independent risk factor for the development of $\mathrm{CVD}^{(1,2)}$ and may be associated with neurodegenerative disease $^{(3,4)}$, diabetes ${ }^{(5)}$ and end-stage renal dysfunction ${ }^{(6,7)}$. Recent in vitro and animal studies have indicated an association between elevated homocysteine (Hcy) levels and the formation of reactive oxygen species, especially the superoxide anion $\left(\mathrm{O}_{2}^{-}\right)$and $\mathrm{H}_{2} \mathrm{O}_{2}{ }^{(8-10)}$, by the auto-oxidation of $\mathrm{Hcy}$ and/or cysteine ${ }^{(11)}$. Intracellular reactive oxygen species production may cause cellular damage ${ }^{(9)}$ and disorders of the antioxidant defence system ${ }^{(12)}$, demonstrating a mechanistic connection between hyperhomocysteinaemia, oxidative stress and disease.

Hcy is an amino acid formed exclusively by demethylation of methionine ${ }^{(13)}$. In Hcy synthesis, methionine is activated by ATP to form S-adenosylmethionine (SAM). SAM acts primarily as a universal methyl donor in the synthesis of methylated compounds such as neurotransmitters (adrenaline, noradrenaline), DNA, RNA, phosphatidylcholine and creatine ${ }^{(14)}$. A subproduct of these methylation reactions is S-adenosylhomocysteine, which is hydrolysed to adenosine and Hcy ${ }^{(15)}$. Hcy can be remethylated to form methionine by the action of the enzyme methionine synthase which uses $N^{5^{\prime} 10}$-methylenetetrahydrofolate-reductase as a methyl donor. The catabolism of methionine is performed by trans-sulfuration, with Hcy reacting with serine to form cystathionine in an irreversible reaction catalysed by cystathione- $\beta$-synthase. Through this pathway, Hcy is converted to cysteine, an important amino acid in the synthesis of proteins and reduced glutathione $(\mathrm{GSH})^{(13)}$.

Creatine is a compound naturally found in food, especially meat and fish, although only half of the daily creatine requirement (about $1 \mathrm{~g} / \mathrm{d}$ ) comes from the diet, while the rest is endogenously synthesised in the liver ${ }^{(16)}$. The first step in creatine synthesis involves the reversible transfer of the amidino group of arginine to glycine to form guanidinoacetic acid (GAA) and ornithine in a reaction catalysed by the enzyme L-arginine:glycine amidinotransferase in the kidneys. Next, the irreversible transfer of a methyl group from SAM to GAA is catalysed by the enzyme SAM:guanidinoacetate $N$-methyltransferase ${ }^{(17)}$. Through this reaction, the endogenous synthesis of creatine consumes a considerable number of methyl groups. In humans, creatine synthesis has been reported to account for $70 \%$ of Hcy formation ${ }^{(18,19)}$. Wyss \& Kaddurah-Daouk ${ }^{(17)}$ reported that this process utilises

Abbreviations: $\mathrm{CrO}+\mathrm{D}$, creatine overload plus diet with creatine; DCr, diet with creatine; GAA, guanidinoacetic acid; GSH, reduced glutathione; Hcy,

homocysteine; SAM, S-adenosylmethionine; TBARS, thiobarbituric acid-reactive species.

* Corresponding author: Rafael Deminice, fax + 55163602 4547, email deminice@ig.com.br 


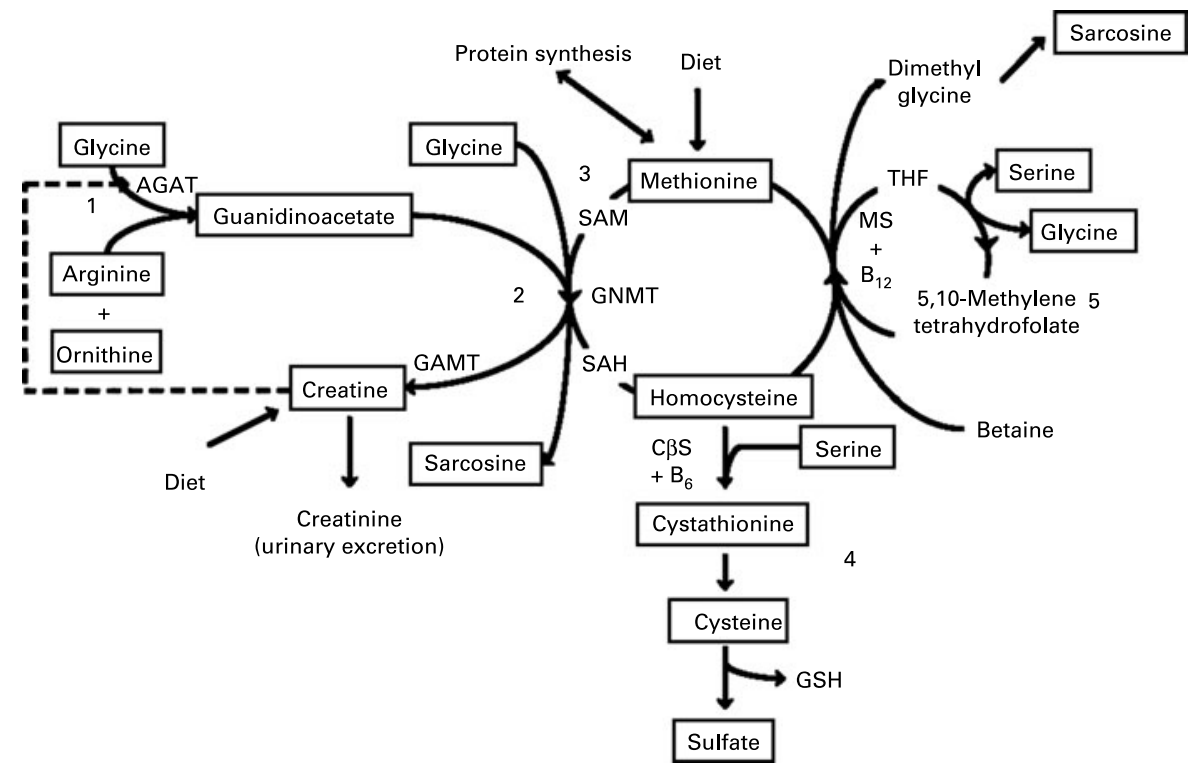

Fig. 1. Schematic presentation of the interaction of homocysteine and creatine metabolism in humans and animals: an increase in creatine intake inhibits the action of the enzyme L-arginine: glycine amidinotransferase (AGAT) required for reaction 1. As consequence, the pathway of S-adenosylmethionine (SAM) to S-adenosylhomocysteine (SAH) is down-regulated and there is a decrease in homocysteine formation (reaction 2). Under normal conditions (normal creatine intake), methionine will interact with guanidinoacetate, forming homocysteine. THF, tetrahydrofolate; MS, methionine synthase; GNMT, glycine $N$-methyltransferase; GAMT, guanidinoacetate methyl-transferase; $\mathrm{C} \beta S$, cystathionine- $\beta$-synthase; GSH, reduced glutathione; reaction 3 , transmethylation; reaction 4 , transsulfuration; reaction 5 , remethylation.

more SAM than all other methyltransferase reactions combined.

Thus, creatine synthesis and Hcy formation are metabolically connected $^{(6)}$ (Fig. 1). Creatine supplementation has been shown to down-regulate the synthesis of L-arginine: glycine amidinotransferase and consequently reduce endogenous formation of creatine, changing the methylation flux and reducing Hcy synthesis ${ }^{(6,20)}$. However, little is known about the possible interactions between methyl balance modulation and lipid peroxidation when Hcy production is decreased by creatine supplementation.

The present study investigated the effects of two protocols of creatine supplementation on plasma levels of Hcy and amino acids involved in Hcy synthesis, and on oxidative stress in healthy rats.

\section{Materials and methods}

\section{Animals and treatment}

Thirty Wistar rats were obtained from the Central Animal House of the Faculty of Medicine of Ribeirão Preto, University of São Paulo, after approval by the institution's Ethics Committee of Animal Experimentation. The animals were kept in individual cages on a $12 \mathrm{~h}$ light $-12 \mathrm{~h}$ dark cycle at a mean temperature of $22^{\circ} \mathrm{C}$ and were divided at random into three groups of ten rats each: control; diet with creatine (DCr); creatine overload plus diet with creatine $(\mathrm{CrO}+\mathrm{D})$. The animals had free access to food and water throughout the experiment.

Creatine supplementation was performed by adding $2 \%$ monohydrate creatine (Acros Organics, Fair Lawn, NJ, USA) to the control diet (AIN-93) ${ }^{(21)}$ for the DCr group for 4 weeks. The $\mathrm{DCr}+\mathrm{O}$ group received monohydrated creatine
$(5 \mathrm{~g} / \mathrm{kg})$ by oral administration for the first $5 \mathrm{~d}$, followed by maintenance with the $2 \%$ creatine diet until the end of the 4-week period (adapted from Hultman et al. ${ }^{(22)}$ ). The animals received fresh food every $2 \mathrm{~d}$. Food intake and weight were measured weekly throughout the study period.

At the end of 4 weeks, $24 \mathrm{~h}$ urine samples were collected from the metabolism cages before the animals were killed by decapitation. Blood was collected and centrifuged and plasma was stored at $-70^{\circ} \mathrm{C}$. The liver and soleus muscle were removed, weighed, immediately frozen in liquid $\mathrm{N}_{2}$ $\left(-196^{\circ} \mathrm{C}\right)$ and stored at $-70^{\circ} \mathrm{C}$.

\section{Measurement of metabolites}

The determination of plasma Hcy levels involves preliminary pretreatment of the sample with S-adenosylhomocysteine hydrolase and dithiothreitol to release Hcy from the proteinbound form. Plasma Hcy, vitamin $\mathrm{B}_{12}$ and folate were determined by competitive immunoassay (IMMULITE ${ }^{\circledR}$ kit; DPC MedLab, Los Angeles, CA, USA). Plasma concentrations of methionine, sarcosine, glycine, serine, ornithine and cystathionine were determined by GC (GC-17A; Shimadzu ${ }^{\circledR}$, Kyoto, Japan) with amino acid derivatisation by the EZ: Faast Amino Acid Analysis kit (Phenomenex ${ }^{\circledR}$, Torrance, CA, USA).

Total GSH was determined in plasma and liver as described by Sedlack \& Lindsay ${ }^{(23)}$. TBARS and total peroxide, as parameters of lipid peroxidation, were determined in plasma and liver by the methods of Mihara \& Uchiyama ${ }^{(24)}$ and Södergren et al. ${ }^{(25)}$, respectively. Plasma and liver $\alpha$-tocopherol was determined by HPLC (LC-20A; Shimadzu ${ }^{\circledR}$ ) as described by Jordão et al. ${ }^{(26)}$.

Plasma, urine and muscle creatine was determined by the Jaffe reaction using a method adapted from Taussky ${ }^{(27)}$ 
and De Saedeleer \& Marechal $^{(28)}$. Samples were heated to convert creatine to creatinine, which reacts with picric acid in an alkaline medium, forming a reddish complex that is measured photometrically. For the assay, $600 \mu \mathrm{l}$ of $44.4 \mathrm{~mm}$ picric acid were added to $200 \mu \mathrm{l}$ of the sample and homogenised. From each sample, $300 \mu \mathrm{l}$ were added to two tubes containing $300 \mu \mathrm{l}$ distilled water $\left(\mathrm{A}_{1}\right.$ and $\left.\mathrm{B}_{1}\right)$. After heating one $\left(\mathrm{A}_{1}\right)$ to $100^{\circ} \mathrm{C}$ for $1.5 \mathrm{~h}$ in a sealed vial, $1 \mathrm{ml}$ of buffer solution containing $208 \mathrm{~mm}$-sodium hydroxide, $12.7 \mathrm{~mm}$-sodium tetraborate and a surfactant was added to all samples $\left(A_{1}\right.$ and $\left.\mathrm{B}_{1}\right)$. Readings were obtained with a spectrophotometer at $510 \mathrm{~nm}$ after incubation at $37^{\circ} \mathrm{C}$ for $10 \mathrm{~min}$ in a water-bath. Absorbances were defined as $\mathrm{A}_{1}$ and $\mathrm{B}_{1}$. After the addition of $100 \mu \mathrm{l}$ of $11.4 \mathrm{~mm}$-acetic acid and incubation at room temperature for $5 \mathrm{~min}$, readings were obtained again and absorbances defined as $A_{2}$ and $B_{2}$. Creatine concentration was calculated by the formula $\left(\mathrm{A}_{1}-\mathrm{B}_{1}\right)-\left(\mathrm{A}_{2}-\mathrm{B}_{2}\right)$ using a standard curve of 5 to $1000 \mu \mathrm{M}$-creatine carried out in triplicate. To determine urinary creatine, $200 \mu \mathrm{l}$ urine were diluted $1: 25$ in $4.8 \mathrm{ml}$ distilled water and processed as described above.

For the determination of muscle creatine, the soleus muscle was weighed, macerated in liquid $\mathrm{N}_{2}$ and homogenised in $1 \mathrm{ml}$ distilled water. The homogenate was diluted to $5 \mathrm{ml}$ by the addition of distilled water $(1: 5)$ and free creatine was determined by the procedure described above. Total muscle creatine was determined by phosphocreatine hydrolysis. For this procedure, $300 \mu \mathrm{l}$ of muscle homogenate were heated to $65^{\circ} \mathrm{C}$ for $10 \mathrm{~min}$ in $0.4 \mu \mathrm{M}-\mathrm{HCl}$ and neutralised with $2 \mu \mathrm{M}-\mathrm{NaOH}$, followed by the creatine measurement procedure described above. Total creatine corresponded to the sum of free creatine and phosphocreatine. Urinary creatinine was determined using an enzymic kit (LABTEST ${ }^{\circledR}$; Labtest Diagnóstica, Lagoa Santa, Minas Gerais, Brazil).

\section{Statistical analysis}

Data are reported as mean values and standard deviations, and groups were compared by ANOVA followed by the Tukey post test. Correlation coefficients were calculated to determine possible within-group associations between variables. In all analyses, the level of significance was set at $P<0 \cdot 05$.

\section{Results}

Table 1 presents the general and biochemical characteristics of the animals in the present study. No significant differences in body-weight gain, food intake, urinary creatinine or intramuscular creatine concentrations were detected between groups. Plasma folate was significantly decreased in the $\mathrm{CrO}+\mathrm{D}$ group, which received dietary and overload creatine, compared with the control group, the no-creatine control. There was a significant increase in plasma and urinary creatine, and in phosphocreatine concentrations for the DCr (dietary creatine only) and $\mathrm{CrO}+\mathrm{D}$ groups compared with the control group. A significant increase of total creatine was observed only in the $\mathrm{CrO}+\mathrm{D}$ group.

Figure 2 presents the plasma Hcy and methionine levels of the experimental groups after 4 weeks of creatine supplementation. A significant decrease in plasma Hcy was observed for the $\mathrm{DCr}(7.5(\mathrm{SD} \mathrm{1.2)} \mu \mathrm{mol} / \mathrm{l})$ and $\mathrm{CrO}+\mathrm{D}(7.2$ (SD 1.7) $\mu \mathrm{mol} / \mathrm{l})$ groups compared with the control group (12.4 (SD 2.2) $\mu \mathrm{mol} / \mathrm{l})$. The reduction detected in the $\mathrm{DCr}$ and $\mathrm{CrO}+\mathrm{D}$ groups compared with the control group was 39 and $41 \%$, respectively. In contrast, no differences were observed in methionine concentration. Significant negative correlations $(P<0.05)$ were detected between plasma Hcy and both plasma creatine (Fig. 3 (A)) and total intramuscular creatine $(r-0.44)$.

Table 2 presents the plasma concentrations of amino acids related to Hcy metabolism. A significant increase in glycine concentration was detected only in the $\mathrm{CrO}+\mathrm{D}$ group compared with the others, whereas cystathionine was reduced in all groups supplemented with creatine compared with the control group. No differences in sarcosine, serine or ornithine were detected.

Table 3 presents the concentration of lipid peroxidation biomarkers and antioxidants in plasma and in liver. Plasma TBARS were significantly reduced after creatine supplementation, as was total plasma GSH. This reduction was not detected in the liver for the $\mathrm{DCr}$ group, however.

Table 1. Comparison of the general and biochemical characteristics of the control, dietary creatine (DCr) and creatine overload plus diet $(\mathrm{CrO}+\mathrm{D})$ groups after 4 weeks of experimentation

(Mean values and standard deviations)

\begin{tabular}{|c|c|c|c|c|c|c|}
\hline & \multicolumn{2}{|c|}{ Control } & \multicolumn{2}{|c|}{$\mathrm{DCr}$} & \multicolumn{2}{|c|}{$\mathrm{CrO}+\mathrm{D}$} \\
\hline & Mean & SD & Mean & SD & Mean & SD \\
\hline Weight gain $(\mathrm{g})$ & $179 \cdot 3$ & $20 \cdot 3$ & 173.7 & 35.5 & $175 \cdot 1$ & $29 \cdot 0$ \\
\hline Food intake $(\mathrm{g} / \mathrm{d})$ & $22 \cdot 7$ & $2 \cdot 8$ & $20 \cdot 3$ & 3.4 & $20 \cdot 1$ & $3 \cdot 2$ \\
\hline Plasma folate $(\mathrm{nmol} / \mathrm{l})$ & $141 \cdot 2^{\mathrm{a}}$ & 22.4 & $119 \cdot 4^{\mathrm{a}}$ & 29.5 & $103 \cdot 7^{\mathrm{b}}$ & $24 \cdot 1$ \\
\hline Plasma vitamin $\mathrm{B}_{12}(\mathrm{pmol} / \mathrm{l})$ & $2676 \cdot 8$ & $136 \cdot 9$ & $2778 \cdot 8$ & $160 \cdot 5$ & $2711 \cdot 2$ & $152 \cdot 0$ \\
\hline Urinary creatinine (mg/24 h) & $5 \cdot 7$ & 1.8 & $7 \cdot 7$ & $2 \cdot 0$ & $6 \cdot 4$ & $2 \cdot 0$ \\
\hline Plasma creatine $(\mu \mathrm{mol} / \mathrm{l})$ & $80 \cdot 1^{a}$ & $26 \cdot 9$ & $191 \cdot 5^{\mathrm{b}}$ & 41.4 & $204 \cdot 8^{\mathrm{b}}$ & $29 \cdot 8$ \\
\hline Intramuscular creatine ( $\mu \mathrm{mol} / \mathrm{g}$ wet weight) & $15 \cdot 7$ & 0.8 & $14 \cdot 8$ & 1.6 & $15 \cdot 1$ & 1.4 \\
\hline Intramuscular $\mathrm{PCr}(\mu \mathrm{mol} / \mathrm{g}$ wet weight) & $2 \cdot 0^{\mathrm{a}}$ & 0.7 & $4 \cdot 34^{\mathrm{b}}$ & $2 \cdot 3$ & $5.91^{b}$ & $1 \cdot 12$ \\
\hline Intramuscular $\mathrm{tCr}$ ( $\mu \mathrm{mol} / \mathrm{g}$ wet weight) & $17 \cdot 8^{a}$ & $1 \cdot 1$ & $19 \cdot 1^{a}$ & 3.4 & $21 \cdot 0^{\mathrm{b}}$ & 1.8 \\
\hline Urinary creatine $(\mu \mathrm{mol} / 24 \mathrm{~h})$ & $0.4^{\mathrm{a}}$ & 0.3 & $2 \cdot 5^{\mathrm{b}}$ & 1.0 & $1 \cdot 7^{\mathrm{b}}$ & 0.7 \\
\hline
\end{tabular}

$\mathrm{PCr}$, phosphocreatine; tCr, total creatine.

a,b Mean values within a row with unlike letters were significantly different $(P<0.05$; ANOVA followed by the Tukey post test). 

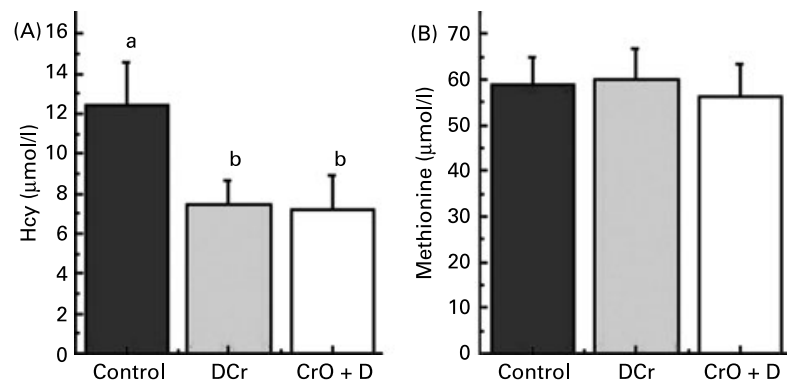

Fig. 2. Effects of 4 weeks of creatine supplementation on plasma homocysteine (Hcy) (A) and methionine (B) levels in the control, dietary creatine $(\mathrm{DCr})$ and creatine overload plus diet $(\mathrm{CrO}+\mathrm{D})$ groups. Values are means, with standard deviations represented by vertical bars. ${ }^{\mathrm{a}, \mathrm{b}}$ Mean values with unlike letters were significantly different $(P<0.05$; ANOVA followed by the Tukey post test).

No differences were observed for total peroxide concentration in plasma, or for $\alpha$-tocopherol in liver or plasma (Table 3 ).

A significant correlation $(P<0 \cdot 05)$ was detected between plasma Hcy and plasma TBARS concentration (Fig. 3 (B)) and a significant negative correlation between plasma creatine and plasma TBARS (Fig. 3 (C)). Significant negative correlations $(P<0 \cdot 05)$ were also found between plasma total peroxide and plasma creatine $(r-0 \cdot 40)$. In addition, significant correlations were detected between folate and Hcy ( $r$ 0.57). The amino acid glycine was correlated with Hcy concentration $(r-0.45)$, plasma total GSH $(r-0.54)$, plasma TBARS $(r-0.52)$ and total peroxides $(r-0.37)$. The amino acid cystathionine was correlated with Hcy concentration $(r 0.50)$, total plasma ( $r$ 0.38) and liver ( $r$ 0.54) GSH.

\section{Discussion}

The present study demonstrated that the Hultman et al. ${ }^{(22)}$ adapted protocol with an overload supplementation period led to significant increases in plasma $(154 \%)$ and total intramuscular creatine $(18 \%)$ concentrations for the $\mathrm{CrO}+\mathrm{D}$ group in relation to the control group. In contrast, the addition of $2 \%$ of creatine in the diet led to a significant increase just in plasma creatine $(139 \%)$ concentrations for the DCr group (Table 1). Hultman et al. ${ }^{(2)}$, in a pioneering study on human subjects, demonstrated that supplementation with $20 \mathrm{~g}$ creatine/d for $6 \mathrm{~d}$ increased the intramuscular stores of creatine by $20 \%$. After this period, the concentration gradually decreased to baseline values, but elevated values of intramuscular creatine concentration were maintained for $30 \mathrm{~d}$ by ingestion of $2 \mathrm{~g} / \mathrm{d}$. The objective of the overload phase is to reach the maximal accumulation in muscular creatine; after this, the levels of muscle creatine can be maintained with relatively small dosages. Therefore, regimens of a loading phase followed by a maintenance phase appear to be effective in increasing total intramuscular creatine levels in rats.

Although there was a significant difference between the supplementation protocols in creatine levels, the same significant reductions in plasma Hcy concentrations were observed in both the $\mathrm{DCr}$ and $\mathrm{CrO}+\mathrm{D}$ groups compared with the control group, with no changes in methionine concentration (Fig. 2 (B)), and significant negative correlations were seen between Hcy and plasma creatine (Fig. 3 (A)). Taken together, these data confirm the hypothesis that creatine
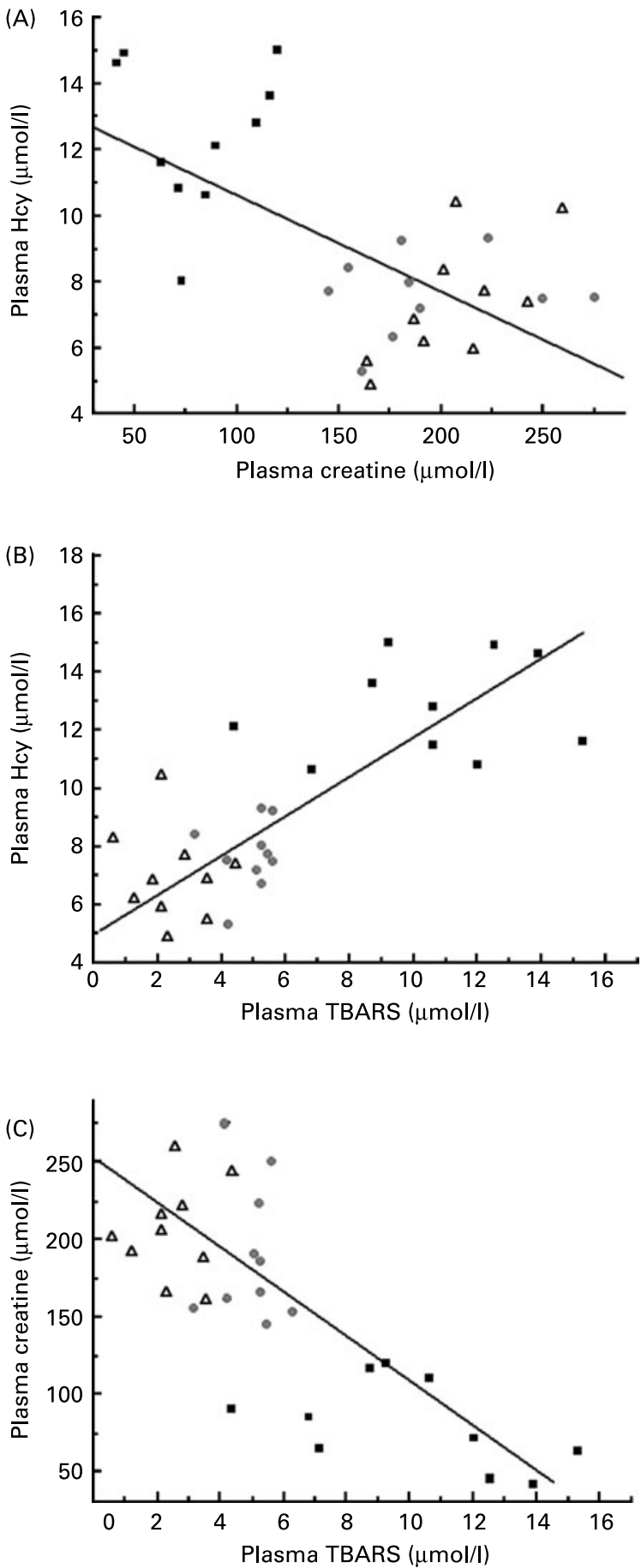

Fig. 3. Linear regression demonstrating a significant negative relationship $(r-0.61 ; P<0.01)$ between homocysteine (Hcy) and plasma creatine $(\mathrm{A})$, a significant positive relationship $(r 0.74 ; P<0.01)$ between plasma Hcy and thiobarbituric acid-reactive species (TBARS) (B) and a significant negative relationship $(r-0.75 ; P<0.01)$ between plasma creatine and plasma TBARS (C). The graphs present the data for all experimental groups: control ( $\square$ ), dietary creatine $(\circlearrowleft)$ and creatine overload plus diet $(\triangle)$.

supplementation reduces plasma Hcy levels in rats. Although no difference was detected between $\mathrm{DCr}$ and $\mathrm{CrO}+\mathrm{D}$ animals, this was the first study to compare Hcy levels after applying different protocols of creatine supplementation. Previous animal studies have also detected reduced Hcy 
Table 2. Plasma levels of the amino acids involved in the metabolism of homocysteine for the control, dietary creatine ( $\mathrm{DCr})$ and creatine overload plus diet $(\mathrm{CrO}+\mathrm{D})$ groups after 4 weeks of experimentation

(Mean values and standard deviations)

\begin{tabular}{|c|c|c|c|c|c|c|}
\hline & \multicolumn{2}{|c|}{ Control } & \multicolumn{2}{|c|}{$\mathrm{DCr}$} & \multicolumn{2}{|c|}{$\mathrm{CrO}+\mathrm{D}$} \\
\hline & Mean & SD & Mean & SD & Mean & SD \\
\hline Sarcosine $(\mu \mathrm{mol} / \mathrm{l})$ & $2 \cdot 4$ & 0.5 & $4 \cdot 1$ & $2 \cdot 0$ & 4.2 & 1.4 \\
\hline Glycine $(\mu \mathrm{mol} / \mathrm{l})$ & $544 \cdot 8^{\mathrm{a}}$ & $121 \cdot 0$ & $594.4^{\mathrm{a}}$ & 89.0 & $682 \cdot 3^{\mathrm{b}}$ & $118 \cdot 0$ \\
\hline Serine $(\mu \mathrm{mol} / \mathrm{l})$ & $410 \cdot 9$ & 86.4 & 394.8 & $77 \cdot 1$ & 405 & $67 \cdot 2$ \\
\hline Ornithine $(\mu \mathrm{mol} / \mathrm{l})$ & 23.9 & $4 \cdot 3$ & $20 \cdot 2$ & 3.5 & $23 \cdot 2$ & 5.6 \\
\hline Cystathionine $(\mu \mathrm{mol} / \mathrm{l})$ & $7 \cdot 0^{\mathrm{a}}$ & 5.5 & $1 \cdot 7^{\mathrm{b}}$ & 0.7 & $1 \cdot 2^{b}$ & 0.8 \\
\hline
\end{tabular}

${ }^{a, b}$ Mean values within a row with unlike letters were significantly different $(P<0.05$; ANOVA followed by the Tukey post test).

concentrations after creatine supplementation ${ }^{(6,20)}$. Stead et al. ${ }^{(20)}$ studied how methylation demand and Hcy formation were modulated by creatine and GAA intake, using rats receiving either $0.4 \%$ creatine, $0.36 \%$ GAA or a control diet. Hcy levels were reduced $25 \%$ by creatine, and increased $50 \%$ with GAA, while plasma methionine levels were unchanged. Taes et al. ${ }^{(6)}$ also detected significant reductions in plasma Hcy levels in a group of nephrectomised rats fed $2 \%$ creatine for 2 weeks, as well as a significant negative correlation between Hcy and plasma creatine.

In contrast to the animal data, studies conducted in human subjects have been somewhat controversial. Norlund et al. ${ }^{\text {(29) }}$ demonstrated a significant correlation between plasma Hcy and serum creatine, and suggested that creatine turnover may be a factor determining Hcy levels. Korzun ${ }^{(30)}$ studied healthy human subjects of both sexes who received creatine for $28 \mathrm{~d}$ and detected a small but significant reduction of Hcy levels compared with controls. In contrast, Steenge et $a l .{ }^{(31)}$, in a study on women ingesting either a placebo or $20 \mathrm{~g}$ creatine/d for $5 \mathrm{~d}$ plus $3 \mathrm{~g}$ creatine/d for 8 weeks, did not find a significant difference in Hcy concentrations in any of the groups after the intervention. These authors also concluded that $61 \mathrm{~d}$ creatine supplementation did not suppress endogenous synthesis to an extent that would affect plasma Hcy levels in healthy women. Taes et al. ${ }^{(7)}$ also found no changes in Hcy levels after creatine supplementation at $2 \mathrm{~g} / \mathrm{d}$ for $28 \mathrm{~d}$ in chronic renal patients on haemodialysis, since the subjects were also receiving vitamins $\mathrm{B}_{6}, \mathrm{~B}_{12}$ and folate. These authors also discussed the possibility that vitamin supplementation can mask the expected fall in Hcy levels in the presence of creatine supplementation. Thus, studies conducted on animals have demonstrated that inhibition of the endogenous methylation demand by creatine supplementation can reduce Hcy levels, but these results have not been reproduced in human subjects.

Creatine supplementation was associated with a decrease in folate concentration, different from Taes et al. ${ }^{(6)}$ who found a folate-saving effect induced by creatine supplementation. The importance of folate in remethylation and for Hcy level is well known $^{(7,8)}$. House et al. ${ }^{(32)}$ related that folate is required in the metabolic pathway for several amino acids, including glycine, serine and methionine and showed a marked elevation in glycine concentration in prolonged folate deficiency. In the present study, the decrease in folate and increase in glycine concentrations in the $\mathrm{CrO}+\mathrm{D}$ group demonstrate the modulation of the flux through remethylation induced by creatine supplementation. These mechanisms appear to be down-regulated to maintain the normal methionine levels (Fig. 2 (B)) while the repression on L-arginine:glycine amidinotransferase exerted by exogenous creatine permits conservation of the amino acid methionine ${ }^{(20)}$. However, further research is required confirming these hypotheses.

Recent studies have also demonstrated the importance of some amino acids on methionine metabolism ${ }^{(14,33)}$. Fukada

Table 3. Biomarkers of oxidative stress and the antioxidant defence system in the plasma and liver of the control, dietary creatine (DCr) and creatine overload plus diet $(\mathrm{CrO}+\mathrm{D})$ groups after 4 weeks of experimentation (Mean values and standard deviations)

\begin{tabular}{|c|c|c|c|c|c|c|}
\hline & \multicolumn{2}{|c|}{ Control } & \multicolumn{2}{|c|}{$\mathrm{DCr}$} & \multicolumn{2}{|c|}{$\mathrm{CrO}+\mathrm{D}$} \\
\hline & Mean & SD & Mean & SD & Mean & SD \\
\hline \multicolumn{7}{|l|}{ Plasma } \\
\hline TBARS $(\mu \mathrm{mol} / \mathrm{l})$ & $10 \cdot 0^{\mathrm{a}}$ & 3.4 & $4.9^{\mathrm{b}}$ & 0.7 & $2 \cdot 4^{\mathrm{C}}$ & 1.0 \\
\hline Total peroxide ( $\mu \mathrm{mol} \mathrm{H}_{2} \mathrm{O}_{2}$ equivalents/l) & $41 \cdot 2$ & $6 \cdot 3$ & 37.8 & $10 \cdot 2$ & 34.6 & $6 \cdot 9$ \\
\hline Total GSH $(\mu \mathrm{mol} / \mathrm{l})$ & $4 \cdot 3^{\mathrm{a}}$ & 1.9 & $2 \cdot 5^{\mathrm{b}}$ & 0.8 & $1 \cdot 8^{\mathrm{b}}$ & 0.5 \\
\hline$\alpha$-Tocopherol $(\mu \mathrm{mol} / \mathrm{l})$ & $26 \cdot 2$ & $6 \cdot 1$ & 20.5 & $5 \cdot 1$ & 18.9 & 3.7 \\
\hline \multicolumn{7}{|l|}{ Liver } \\
\hline TBARS (nmol/mg protein) & $0.13^{a}$ & 0.01 & $0.18^{\mathrm{b}}$ & 0.01 & $0.12^{\mathrm{a}}$ & 0.01 \\
\hline Total GSH (mmol/mg protein) & $44 \cdot 0^{\mathrm{a}}$ & $10 \cdot 0$ & $34 \cdot 1^{\mathrm{a}}$ & $14 \cdot 2$ & $29 \cdot 4^{\mathrm{b}}$ & $10 \cdot 0$ \\
\hline$\alpha$-Tocopherol $(\mu \mathrm{mol} / \mathrm{l})$ & $76 \cdot 8$ & $12 \cdot 0$ & $82 \cdot 8$ & $15 \cdot 7$ & $87 \cdot 6$ & $27 \cdot 4$ \\
\hline
\end{tabular}

TBARS, thiobarbituric acid-reactive species; GSH, reduced glutathione.

a,b,c Mean values within a row with unlike letters were significantly different $(P<0.05$; ANOVA followed by the Tukey post test). 
et al. ${ }^{(33)}$ showed the hypohomocysteinaemic effect of glycine and serine in animals loaded with an excess of methionine. In the present study, the glycine sparing effect in the $\mathrm{CrO}+\mathrm{D}$ group compared with the control group (Table 2), along with the negative correlations between glycine and Hcy, suggests that the action of methyl-group acceptor of glycine is not required when Hcy formation is inhibited (Fig. 1, reaction 2). In addition, this sparing effect can also indicate an inhibition of the one-carbon unit-providing action of glycine to the $N^{5^{\prime} 10}$-methylene-tetrahydrofolate-dependent remethylation of Hcy (Fig. 1, reaction 5). Thus, it seems reasonable to consider the important role of glycine on Hcy-modulated metabolism induced by creatine supplementation.

Although some authors have demonstrated an association between hyperhomocysteinaemia and free radical formation $^{(8-10)}$, the present study is the first to demonstrate that the reduction of plasma Hcy levels by creatine supplementation is associated with a significant reduction of plasma lipid peroxidation biomarkers (Table 3). Also, the significant negative correlations between plasma creatine and the plasma lipid peroxidation biomarkers (TBARS and total peroxide) (Fig. 3 (C)) are in vivo confirmation of in vitro findings on the potential of creatine to remove reactive oxygen species ${ }^{(34,35)}$ and act as an antioxidant in a dosedependent response. Lawler et al. ${ }^{(34)}$ demonstrated a direct dose-response relationship of creatine concentration with superoxide anion $\left(\mathrm{O}_{2}^{-}\right)$, peroxynitrite $\left(\mathrm{OONO}^{-}\right)$and $2,2^{\prime}$ azino-bis(3-ethylbenzothiazoline-6-sulfonic acid) (ABTS) as determined by the rate of renewal of the $\mathrm{ABTS}^{+}$radical, and concluded that creatine has a significant role as an antioxidant. The authors state, however, that this potential appears to be lower than the normal physiological levels of GSH. Sestili et al. ${ }^{(35)}$ also demonstrated that creatine has a direct antioxidant activity on cultured cells exposed to different oxidative agents. These authors verified that creatine, at doses similar to those detected in plasma after supplementation, had an antioxidant cytoprotective activity on three cell lines against three different oxidative agents: $\mathrm{H}_{2} \mathrm{O}_{2}, \mathrm{OONO}^{-}$and tertbutylhydroperoxide (tB-OOH). In addition, the cytoprotection was independent of the antioxidant status of the catalase and glutathione peroxidase enzymes, suggesting a direct interaction between creatine and oxidant and/or free radicals. Souza et al. ${ }^{(36)}$ assayed the chemiluminescence of excited carbonyls in urine, as a measure of the extent of tissue lipid peroxidation. In a study on the effects of different types of exercise, they found that lipid peroxidation in individuals who performed force/hypertrophy training with creatine supplementation was significantly lower than in a placebo group, suggesting protective antioxidant effects of creatine. However, in the present study, the antioxidant effect found in the plasma was not observed in the liver, suggesting that the antioxidant effects of creatine can be different in these tissues. Several investigators have suggested, however, that the antioxidant effects of creatine can be attributed to indirect antioxidant mechanisms such as hydration, membrane stabilisation and improved energy capacity of the cell ${ }^{(1,16)}$. The potential of creatine supplementation for the reduction of Hcy levels and consequently of cell toxicity that is demonstrated in the present study may also be an indirect form of the antioxidant action of this substance.

Hcy is the key intermediate in the coordination of the transsulfuration and remethylation pathways and its production may influence the synthesis and function of methionine and $\mathrm{GSH}^{(37)}$. GSH is the most abundant thiol in the antioxidant defence system, directly acting to neutralise reactive oxygen species ${ }^{(38)}$. In the present study, the significant reductions of liver and plasma GSH (Table 3) and cystathionine concentrations (Table 2), in addition to the significant correlation between these two compounds, suggested that modulation of the methyl balance and the consequent reduction of Hcy can down-regulate the trans-sulfuration pathway in a dose-dependent response. This might decrease GSH production, affecting the redox status of the cells. Martinov et al. ${ }^{(39)}$, in a mathematical modelling study of SAM metabolism in the liver, stated that when SAM levels are low, priority for this substrate goes to transmethylation reactions, promoting reduction of the trans-sulfuration pathway. These findings demonstrate the important relationship between the processes of methylation, Hcy formation and GSH formation.

In conclusion, creatine supplementation by the two protocols studied reduced plasma Hcy concentrations, possibly by modulating the methyl balance. This reduction of Hcy was associated with reduced lipid peroxidation biomarkers, suggesting the in vivo antioxidant cytoprotective effect of creatine. Alternatively, creatine supplementation might modulate the bioavailability of Hcy for the remethylation and transsulfuration processes, in turn influencing GSH synthesis, and affecting the redox status of the cells. Future studies should include a larger number of oxidative stress biomarkers and antioxidants, to determine the specific link with Hcy metabolism and changes induced by creatine supplementation.

\section{Acknowledgements}

We thank the technical laboratory Lívia Simões-Ambrosio, University of Sao Paulo, Ribeirão Preto, for help in the analysis of Hcy, vitamin $B_{12}$ and folate.

The present study was supported by Brazilian funds from CAPES (Coordenação de Aperfeiçoamento do Ensino Superior), CNPq (Conselho Nacional de Desenvolvimento Cientifico e Tecnológico) and FAPESP (Fundação de Amparo a Pesquisa do Estado de São Paulo, Proc. 2006/ 00946-8).

R. D. was a post-graduate student and author of the work; G. V. P. collaborated with post-graduate student R. D., including collection and analysis of data and significant help in the laboratory; H. V. was chief of the Laboratory of Nutrition and co-chief of the scientific project; A. A. J. was chief of the Nutrition and Metabolism Laboratory, the scientific project and of the post-graduate students.

All the authors declare that there are no potential conflicts of interest.

\section{References}

1. Wyss M \& Schulze A (2002) Health implications of creatine: can oral creatine supplementation protect against neurological and atherosclerotic disease? Neuroscience 112, 243-260.

2. Harbor-Gonçalves L, Vaz LS \& Bezzi M (2005) Associação entre níveis plasmáticos de homocisteína e acidente vascular cerebral isquêmico (Association between plasma homocysteine 
levels and ischaemic cerebral vascular accident). Arq Neuropsiquiatr 63, 97-103.

3. Obeid R \& Herrmann W (2006) Mechanisms of homocysteine neurotoxicity in neurodegenerative diseases with special reference to dementia. FEBS Lett 580, 2994-3005.

4. Bender A, Koch W, Elstner M, et al. (2006) Creatine supplementation in Parkinson disease: a placebo-controlled randomized pilot trial. Neurology 67, 1262-1264.

5. Wijekoon EP, Brosnan ME \& Brosnan JT (2007) Homocysteine metabolism in diabetes. Biochem Soc Trans 35, 1175-1179.

6. Taes YE, Delanghe JR, De Vriese AS, et al. (2003) Creatine supplementation decreases homocysteine in an animal model of uremia. Kidney Int 64, 1331-1337.

7. Taes YE, Delanghe JR, De Bacquer D, et al. (2004) Creatine supplementation does not decrease total plasma homocysteine in chronic hemodialysis patients. Kidney Int 66, 2422-2428.

8. Huang RF, Hsu YC, Lin HL, et al. (2001) Folate depletion and elevated plasma homocysteine promote oxidative stress in rat livers. J Nutr 131, 33-38.

9. Streck EL, Vieira PS, Wannmacher CM, et al. (2003) In vitro effect of homocysteine on some parameters of oxidative stress in rat hippocampus. Metab Brain Dis 18, 147-154.

10. Weiss N (2005) Mechanisms of increased vascular oxidant stress in hyperhomocysteinemia and its impact on endothelial function. Curr Drug Metab 6, 27-36.

11. Hogg N (1999) The effect of cyst(e)ine on the auto-oxidation of homocysteine. Free Radic Biol Med 27, 28-33.

12. Blundell G, Jones BG, Rose FA, et al. (1996) Homocysteine mediated endothelial cell toxicity and its amelioration. Atherosclerosis 122, 163-172.

13. Brosnan JT, Jacobs RL, Stead LM, et al. (2004) Methylation demand: a key determinant of homocysteine metabolism. Act Biol Pol 51, 405-413.

14. Brosnan JT, da Silva R \& Brosnan ME (2007) Amino acids and the regulation of methyl balance in humans. Curr Opin Clin Nutr Metab Care 10, 52-57.

15. Selhub J (1999) Homocysteine metabolism. Annu Rev Nutr 19, 217-246.

16. Persky AM \& Brazeau GA (2001) Clinical pharmacology of the dietary supplement creatine monohydrate. Pharmacol Rev 53, $161-176$

17. Wyss M \& Kaddurah-Daouk R (2000) Creatine and creatinine metabolism. Physiol Rev 80, 1107-1213.

18. Mudd SH \& Poole JR (1975) Labile methyl balances for normal humans on various dietary regimens. Metabolism 24, $721-735$

19. Mudd SH, Ebert MH \& Scriver CR (1980) Labile methyl group balances in the human: the role of sarcosine. Metabolism 29, $707-720$

20. Stead LM, Au KP, Jacobs RL, et al. (2001) Methylation demand and homocysteine metabolism: effects of dietary provision of creatine and guanidinoacetate. Am $J$ Physiol Endocrinol Metab 281, E1095-E1100.

21. Reeves PG, Nielsen FH \& Fahey GC Jr (1993) AIN-93 purified diets for laboratory rodents: final report of the American Institute of Nutrition ad hoc writing committee on the reformulation of the AIN-76A rodent diet. J Nutr 123, 1939-1951.

22. Hultman E, Soderlund K, Timmons JA, et al. (1996) Muscle creatine loading in men. $J$ Appl Physiol 81, 232-237.
23. Sedlak J \& Lindsay RH (1968) Estimation of total, proteinbound, and nonprotein sulfhydryl groups in tissue with Ellman's reagent. Anal Biochem 25, 192-205.

24. Mihara M \& Uchiyama M (1978) Determination of malonaldehyde precursor in tissues by thiobarbituric acid test. Anal Biochem 86, 271-278.

25. Södergren E, Nourooz-Zadeh J, Berglund L, et al. (1998) Re-evaluation of the ferrous oxidation in xylenol orange assay for the measurement of plasma lipid hydroperoxides. $J$ Biochem Biophys Methods 18, 137-146.

26. Jordão AA Jr, Chiarello PG, Arantes MR, et al. (2004) Effect of an acute dose of ethanol on lipid peroxidation in rats: action of vitamin E. Food Chem Toxicol 42, 459-464.

27. Taussky HH (1954) A microcolorimetric determination of creatine in urine by the Jaffe reaction. $J$ Biol Chem 208, 853-861.

28. De Saedeleer M \& Marechal G (1984) Chemical energy usage during isometric twitches of frog sartorius muscle intoxicated with an isomer of creatine, $\beta$-guanidinopropionate. Pflugers Arch 402, 185-189.

29. Norlund L, Grubb A, Fex G, et al. (1998) The increase of plasma homocysteine concentrations with age is partly due to the deterioration of renal function as determined by plasma cystatin C. Clin Chem Lab Med 36, 175-178.

30. Korzun WJ (2004) Oral creatine supplements lower plasma homocysteine concentrations in humans. Clin Lab Sci 17, 102-106.

31. Steenge GR, Verhoef P \& Greenhaff PL (2001) The effect of creatine and resistance training on plasma homocysteine concentration in healthy volunteers. Arch Intern Med 161, $1455-1456$.

32. House JD, O'Connor CP \& Guenter W (2003) Plasma homocysteine and glycine are sensitive indices of folate status in a rodent model of folate depletion and repletion. J Agric Food Chem 51, 4461-4467.

33. Fukada S, Shimada Y, Morita T, et al. (2006) Suppression of methionine-induced hyperhomocysteinemia by glycine and serine in rats. Biosci Biotechnol Biochem 70, 2403-2409.

34. Lawler JM, Barnes WS, Wu G, et al. (2002) Direct antioxidant properties of creatine. Biochem Biophys Res Commun 290, $47-52$.

35. Sestili P, Martinelli C, Bravi G, et al. (2006) Creatine supplementation affords cytoprotection in oxidatively injured cultured mammalian cells via direct antioxidant activity. Free Radic Biol Med 40, 837-849.

36. Souza TP Jr, Oliveira PR \& Pereira B (2005) Efeitos do exercício físico intenso sobre a quimioliminescencia urinária e malonaldeido plasmático (Effect of intense physical exercise on the urinary chemiluminescence and plasmatic malonaldehyde). Braz J Sports Med 11, 91-96.

37. Prudova A, Bauman Z, Braun A, et al. (2006) S-adenosylmethionine stabilizes cystathionine $\beta$-synthase and modulates redox capacity. Proc Natl Acad Sci U S A 103, 6489-6494.

38. Feoli AM, Siqueira I, Almeida LM, et al. (2006) Brain glutathione content and glutamate uptake are reduced in rats exposed to pre- and postnatal protein malnutrition. $J$ Nutr 36, $2357-2361$

39. Martinov MV, Vitvitsky VM, Mosharov EV, et al. (2000) A substrate switch: a new mode of regulation in the methionine metabolic pathway. J Theor Biol 204, 521-532. 